\title{
A DICOTOMIA FATO-VALOR E SEU COLAPSO: UM ESTUDO A PARTIR DE HILARY PUTMAM
}

The fact-value dichotomy and its colapse: a study from Hilary Putmam

\author{
Carlos Roberto Bueno Ferreira*
}

Resumo: O presente artigo busca analisar a dicotomia entre fato e valor. A separação do que é meramente fático-objetivo do que é valorativo-subjetivo é resultado de uma progressão histórica fundada numa série de teorias que se opõe entre si, remontando ao embate entre Descartes e Hume (racionalismo e empirismo). Contudo, esta dicotomia é criticada por Hilary Putnam que defende a existência de um entrelaçamento de fatos e valores. Neste artigo buscar-se-á demonstrar o perigo de se defender o ideal de uma ciência livre de valores éticos e sociais. Finalmente, para poder demonstrar de uma maneira mais tangível o entrelaçamento entre fato e valor, utilizar-se-á a crítica à teoria econômica clássica feita por Amartya Sen, que tenta levar em conta que a economia também é uma ciência humana que lida com fatores éticos complexos os quais não podem ser reduzidos simplesmente a números e estatísticas.

Palavras-chave: Dicotomia fato-valor. Hilary Putnam. Entrelaçamento fato-valor. Amartya Sen. Abordagem das capacidades.

\begin{abstract}
This paper analyzes the dichotomy between fact and value. The separation of the merely factual-objetive from what is evaluativesubjective is the result of a historical progression based on a number of theories that oppose each other, going back to the conflict between Descartes and Hume (rationalism and empiricism). However, this dichotomy is criticized by Hilary Putnam, who proposes the existence of an entanglement of facts and values. This article will seek to demonstrate the danger of defending the ideal of science free from ethical and social values. Finally, in order to demonstrate in a more tangible way the entanglement between fact and value, it will use the criticism to classical economic theory made by Amartya Sen, which tries to take into account that economy is also a science that deals with complex human ethical factors which can not be simply reduced to numbers and statistics.
\end{abstract}

Keywords: Fact-value dichotomy. Hilary Putnam. Fact-value entanglement. Amartya Sen. Capability approach.

\footnotetext{
* Mestrado em Filosofia Pontifícia Universidade Católica do Rio Grande do Sul (PUCRS). Bolsista CAPESPROSUP. Contato: crbuenoferreira@gmail.com
}

\begin{tabular}{|c|c|c|c|c|c|}
\hline intuitio & $\begin{array}{c}\text { ISSN } \\
1983-4012\end{array}$ & Porto Alegre & Vol.7- No.1 & $\begin{array}{c}\text { Junho } \\
2014\end{array}$ & p.67-78 \\
\hline
\end{tabular}




\section{Introdução}

A temática relativa à dicotomia fato-valor é uma questão estrutural. Trata-se de assunto basilar que permeia a forma como vemos o conhecimento humano nos dias de hoje. Por muito tempo se buscou não apenas diferenciar fatos de valores, mas criar um abismo intransponível, uma dicotomia, entre observações meramente factuais e juízos de valor. Não à toa, ainda hoje existe a tendência de se considerar a ciência pura como aquela que consiste na busca por afirmações factuais, capazes de produzir verdade objetiva, enquanto juízos valorativos são relacionados a meras impressões pessoais, fora da esfera da razão científica.

O filósofo estadunidense Hilary Putnam trata do assunto em seu livro "The Collapse of the Fact/Value Dichotomy and Ohter Essays", publicado em 2002, ainda sem tradução no Brasil ${ }^{1}$. Trata-se de uma sequência de palestras e artigos onde o autor defende que não haveria uma dicotomia rígida entre fato e valor, mas sim um entrelaçamento, uma indissociabilidade.

A ideia da dicotomia tem sido defendida historicamente remontando ao duelo entre o racional e o empírico, travado por David Hume e Descartes, tendo fundamentos variados, dentre eles, argumentos metafísicos, epistemológicos e lógicos. Putnam enfrenta cada um desses na tentativa de provar que nenhuma forma de dicotomia se sustenta plenamente quando se aborda temas como cognição e semântica ligadas à mente humana.

É nesse sentido que se pretende abordar o assunto da dicotomia fato-valor, partindo do pensamento de Putnam e apontando as possíveis consequências que os argumentos enfrentados pelo autor geram para a percepção filosófica das ciências políticas, e as noções de razão aplicáveis às questões normativas.

\section{A dicotomia fato-valor}

Quem nunca ouviu a seguinte indagação: “Isso é um fato ou um juízo de valor?”. Séculos de debates filosóficos sedimentaram nosso pensamento de forma a presumirmos que "fatos" são constatações objetivas e "valores" são meras impressões subjetivas. Para que se possa chegar ao estado atual das coisas no que tange à dicotomia entre fato e valor devemos relembrar, brevemente, os debates teóricos que contribuíram para a ideia dessa separação.

Inicialmente, Putnam aponta a importância de se respeitar a diferença entre o dualismo filosófico e a distinção ingênua. Uma distinção filosófica pode, de fato, contribuir para uma melhor compreensão de determinado assunto ou ideia. Contudo, no momento em que se passa a tratar uma distinção como uma questão prioritária para a abordagem de qualquer assunto passa-se a criar um dualismo.

${ }^{1}$ PUTNAM, H. The collapse of the fact/value dichotomy and other essays. Cambrige, MA: Harvard Press, 2002.

\begin{tabular}{|c|c|c|c|c|c|}
\hline intuitio & $\begin{array}{c}\text { ISSN } \\
1983-4012\end{array}$ & Porto Alegre & Vol.7- $\mathrm{N}^{\mathrm{o}} .1$ & $\begin{array}{l}\text { Junho } \\
2014\end{array}$ & p. $67-78$ \\
\hline
\end{tabular}


Como exemplo, os positivistas lógicos notadamente introduziram a classificação tripartite entre sentenças analíticas, sintéticas e aquelas que não traduzem significado cognitivo. Analíticas seriam as assertivas passíveis de serem avaliadas como verdadeiras ou falsas, como em: "Todos os solteiros não são casados". Já a verificação de assertivas sintéticas dependeria de uma comprovação, não sendo possível se extrair a verdade de forma imediata, como em: "As estrelas do cinturão de Orion são vermelhas". Por fim, a terceira categoria seria a das assertivas não dotadas de sentido cognitivo (nonsense).

Essa diferenciação foi concebida pelos positivistas como uma avaliação obrigatória, aplicável a toda e qualquer coisa, seja em que contexto estivesse inserida. Se uma assertiva falhasse em ser classificada, logo se procurava uma incongruência que fosse imputável ao prolator da sentença, condenando o pela ambiguidade decorrente. É essa forma de "distinção filosófica" que Putnam procura denominar dualismo, ou mesmo dicotomia.

Um exemplo interessante dessa passagem de distinção inocente para uma dualismo metafísico é a forma como Kant enfrentou a classificação entre o sintético e o analítico. Ao tentar aplicar essa dualidade às verdades matemáticas, Kant chegou à conclusão de que os princípios da matemática eram sintéticos e a priori. Certamente tal conclusão foi rechaçada pelos positivistas, porquanto classificavam verdades matemáticas como analíticas. Contudo, mesmo que não queiramos concordar com a classificação apontada por Kant, devemos estar abertos para a possibilidade de que as verdades matemáticas não sejam nem somente assertivas analíticas, nem sentenças puramente sintéticas.

Isso comprova que as meras distinções filosóficas têm um campo de utilidade ou um contexto próprio para aplicação, e que não ficamos surpresos se elas não se aplicam em determinados casos. É isso que os positivistas parecem não ter compreendido, pois mesmo diante de problemas no momento da classificação, eles continuam a tentar uma adequação forçada para todas as situações.

A simples constatação de diferenças não traz problema algum, entretanto, a necessidade de se classificar todas as assertivas como analíticas ou sintéticas, resolvendo todos os problemas filosóficos de uma só vez é que se mostra insuficiente, pois há casos em que não fica clara a separação entre o que é fato dado e o que depende de uma valoração ou convenção. Algumas sentenças funcionam tanto para produzir enunciados factuais como para gerar juízos de valor. Citando uma famosa passagem de Quine ${ }^{2}$ :

The lore of our fathers is a fabric of sentences. In our hands it develops and changes, through more or less arbitrary and deliberate revisions and additions of our own, more or less directly occasioned by the continuing stimulation of our sense organs. It is a pale grey lore, black with fact and white with convention. But I have found no substantial reasons for concluding that there are any quite black threads in it, or any white ones ${ }^{3}$.

\footnotetext{
${ }^{2}$ Nesse artigo o autor optou por traduzir livremente do inglês todas as passagens citadas, mantendo a versão original para conferência.

${ }^{3}$ QUINE apud PUTNAM, Hilary. The collapse of the fact/ value dichotomy and other essays. Cambrige, MA: Harvard Press, 2002, p. 12.
}

\begin{tabular}{|c|c|c|c|c|c|}
\hline intuitio & $\begin{array}{c}\text { ISSN } \\
1983-4012\end{array}$ & Porto Alegre & Vol.7- $\mathrm{N}^{\mathrm{o}} .1$ & $\begin{array}{l}\text { Junho } \\
2014\end{array}$ & p. $67-78$ \\
\hline
\end{tabular}


O legado dos nossos pais é um tecido de sentenças. Nas nossas mãos ele se desenvolve e muda, através de nossas revisões e adições mais ou menos arbitrárias e deliberadas, mais ou menos ocasionadas diretamente pela contínua estimulação dos nossos órgãos sensitivos. È um legado cinza pálido, preto com fato e branco com convenção. Mas eu não encontrei razões substanciais para concluir que existam quaisquer fios pretos ou brancos nele.).

Nessa analogia, Quine aponta que esse "tecido de sentenças legado pelos nossos pais" é cinza, branco com convenção e preto com fato, contudo o autor entende não haver razões substanciais para concluir que existam fios pretos nem brancos. Isso reforça que esse tecido, que representa a nossa realidade, não pode ser claramente dissociado em fios pretos (significando fatos) e brancos (significando convenção). É justamente essa indissociação que Putnam tenta provar, alegando o entanglement entre fato e valor.

Prosseguindo na evolução teórica, podemos evocar outra dicotomia: a que decorre da "falácia naturalista" como apontada por David Hume: o que "deve ser" não pode ser inferido a partir do que "é”. Putnam tenta mostrar que essa afirmação de Hume pressupõe uma metafísica substancial e não é, como muitos costumam julgar, uma constatação meramente lógica. O que evidencia isso é que Hume não se preocupa meramente com a validade de certas formas de inferência.

A simples formulação de que não se pode inferir "p\&q" de "p" ou "q" não é suficiente para explicar a lei de Hume. Um "dever ser" não pode ser extraído simplesmente da forma de uma outra afirmação, mas sim decorre da compreensão do seu conteúdo. Segundo Putnam, foi assumida uma dicotomia metafísica entre matéria de fato e relação de ideias. Dessa forma, o que Hume quis dizer é que quando uma afirmação de "ser" descreve uma matéria de fato, então nenhum julgamento de "dever ser" pode derivar dela.

Putnam entende que Hume adotou como critério para a constatação de matérias de fato uma "semântica pictórica". Ideias, por outro lado, possuem também características não pictóricas e podem ser facilmente relacionadas com sentimentos. Assim, ao dizer que não se pode inferir um "dever ser" de um "ser", Hume estaria também afirmado que não existem matérias de fato sobre bom, mau, virtude e vício. Se realmente existisse uma matéria fática sobre vício ou virtude, então também deveria ser possível representarem-se as propriedades do vicio ou da virtude de forma pictográfica, do mesmo jeito que se pode representar graficamente uma maçã. Surge aqui uma relação com a dicotomia entre o sintético e o analítico com uma aproximação do "ser" com o factual e do "dever ser" com o valorativo.

Pode-se apontar que os julgamentos de "dever ser" possuem um conteúdo ético como nas palavras: certo e errado. Contudo, classificar matérias fáticas como constatações sintéticas a posteriori e valores éticos ou sentimentos como proposições analíticas não solve os problemas filosóficos levantados. Em outras palavras, pode-se dizer que a dicotomia fato-valor não é, no fundo, uma distinção, mas uma tese de que o ético não é sobre matérias de fato.

\begin{tabular}{|c|c|c|c|c|c|}
\hline intuitio & $\begin{array}{c}\text { ISSN } \\
1983-4012\end{array}$ & Porto Alegre & Vol.7 - $\mathrm{N}^{\circ} .1$ & $\begin{array}{l}\text { Junho } \\
2014\end{array}$ & p.67-78 \\
\hline
\end{tabular}


Com a evolução do mundo científico, a posição dos positivistas lógicos logo foi testada e prevaleceu. Não mais se admitia uma definição de "fato" como impressão sensível, nos moldes humeanos. Tampouco interessava uma avaliação valorativa da ética normativa. Foi imposta a validade de uma indispensável separação entre fato e valor. Contudo, essas nova dicotomia não se baseava em qualquer exame sério sobre valor e normatividade ética, mas sim era focada na definição, de uma forma estritamente empírica, do que era "fato".

O empirismo e o positivismo lógico tratam dados empíricos como fatos observados e confirmados, portanto livres de valores ou convenções. As categorias utilizadas para enunciar fatos puros (bare facts) não possuem implicações ou conotações valorativas. A lei da gravitação de Newton, por exemplo, não pode ser vinculada a nenhum juízo de valor, não fazendo sentido perguntar se a lei é boa ou má (juízo ético) nem se devemos agir de acordo com essa lei (dever ser). A lei de Newton, caso enuncie realmente um mero "fato", trata de apresentar um modelo de como os objetos do mundo realmente são, não havendo juízo de valor entre as suas pressuposições e implicações ${ }^{4}$. Trata-se de uma observação objetiva, livre de valores subjetivos. Dessa maneira, a dicotomia entre fato e valor fica reforçada pela dicotomia entre objetivo e subjetivo.

É aqui que se aplica a crítica de Quine, o qual sugeriu que essa ideia de classificar todos os julgamentos, incluindo os puramente matemáticos, como "factuais" ou "convencionais" seria pura perda de tempo.

\section{0 entrelaçamento (entanglement) fato-valor}

Com efeito, não se sustenta uma divisão pura entre fato e convenção, mesmo os empiristas devem conceder que a ciência pressupõe valores, experiências e convenções. Uma vez que conseguimos separar o significado de "valor" de uma concepção estritamente ética, podemos verificar que a ciência pressupõe valores epistêmicos.

O pragmatismo clássico sustenta que valor e normatividade são parte de toda a experiência humana. Assim, não seria concebível que a ciência buscasse se despir de quaisquer julgamentos de valor, porquanto esses fazem parte essencial da produção científica em si. Julgamentos de valor não são somente os que decorrem de avaliações éticas ou morais, mas também os que convencionam a coerência, a razoabilidade e a racionalidade. Existem, portanto, valores epistêmicos e valores éticos. Valores éticos seriam os expressados em verdades normativas como: "roubar é errado"; valores epistêmicos seriam valores que nos guiam na escolha entre hipóteses sobre a visão correta de mundo (coerência, simplicidade, etc). Valores epistêmicos estariam entrelaçados com a observação objetiva. Isso, contudo, não significa que objetividade seja sinônimo de valor epistêmico. A matemática, segundo Putnam, é um exemplo de descrição objetiva sem que haja um objeto. O ponto aqui é que se

${ }^{4}$ LACEY, Hugh. Valores e atividade científica. São Paulo: Discurso Editorial, 1998.

\begin{tabular}{|c|c|c|c|c|c|}
\hline intuitio & $\begin{array}{c}\text { ISSN } \\
1983-4012\end{array}$ & Porto Alegre & Vol.7- $\mathrm{N}^{\mathrm{o}} .1$ & $\begin{array}{l}\text { Junho } \\
2014\end{array}$ & p. $67-78$ \\
\hline
\end{tabular}


A dicotomia fato-valor e seu colapso: um estudo a partir de Hilary Putmam

deixe de pensar em objetividade de maneira puramente descritiva. A linguagem nos permite descrever o mundo em que vivemos, contudo essa não é sua única função. Ela também nos permite questionar a própria forma como vemos o mundo.

O entrelaçamento entre fato e valor não é somente perceptível no caso dos valores epistêmicos. Ele fica ainda mais evidente se tomarmos conceitos éticos em contextos linguísticos. O vocabulário necessário para que um positivista lógico descreva seus "fatos" é uma ínfima parte do arcabouço comunicativo que nós como seres humanos desenvolvemos para a simples tarefa de interação social.

Putnam utiliza a palavra "cruel" para demonstrar na prática a indissociação entre fato e valor. Tomemos a seguinte frase: "o governador é cruel". Podemos verificar que, ao mesmo tempo foi feita uma crítica ao governador como pessoa e como administrador público. Em todo caso, poderíamos ter dividido a frase em dois contextos semânticos, um relacionado à atuação do governador como pessoa e outro se referindo a sua atitude como administrador, da seguinte forma: "ele é um governador cruel, mas uma ótima pessoa". Ainda, não podemos negar que se faça uma assertiva meramente descritiva utilizando a palavra "cruel", como é o caso de um historiador escrevendo que certo imperador fora cruel com seus inimigos. Não há uma separação nítida entre os predicados usados em uma enunciação fática e os decorrentes de um juízo de valor. Nas palavras de Putnam:

\footnotetext{
"Cruel" simply ignores the supposed fact/ value dichotomy and cheerfully allows itself to be used sometimes for a normative purpose and sometimes as a descriptive term. (Indeed, the same is true of the term "crime.") In the literature, such concepts are often referred to as "thick ethical concepts" 5 .

"Cruel" simplesmente ignora a suposta dicotomia fato/valor e alegremente se permite ser usado às vezes com propósito normativo e às vezes como termo descritivo (de fato, o mesmo é verdade para o termo "crime"). Na literatura, tais conceitos são frequentemente referidos como "thick ethical concepts".
}

Os predicados que podem ser usados simultaneamente para servir a ambos os fins - factuaisdescritivos e valorativos - têm sido chamados de conceitos éticos estritos (thick ethical concepts) em contraposição aos conceitos éticos tênues (thin ethical concepts). Como exemplos de conceitos estritos têm-se as palavras honestidade, justiça, fome, crime, etc. Em suma, podemos dizer que conceitos éticos estritos possuem, ao mesmo tempo, um grau semântico e um conteúdo descritivo, representando, dessa forma, contraprovas à instalação da dicotomia fato-valor. Conforme Lacey:

O uso de termos éticos estritos, no discurso factual não cria um obstáculo para obter resultados que sejam bem confirmados à luz dos valores cognitivos e dados empíricos disponíveis - e quando tais resultados ficam bem confirmados, a avaliação ética fica mais forte. Teorias que contém tais resultados não são neutras: elas fornecem suporte para avaliações éticas particulares ${ }^{6}$.

\footnotetext{
${ }^{5}$ PUTNAM, Hilary. The collapse of the fact/ value dichotomy and other essays. Cambrige, MA: Harvard Press, 2002 , p.35.

${ }^{6}$ LACEY, Hugh. Valores e atividade científica. São Paulo: Discurso Editorial, 1998, p. 258.
}

\begin{tabular}{|c|c|c|c|c|c|}
\hline intuitio & $\begin{array}{c}\text { ISSN } \\
1983-4012\end{array}$ & Porto Alegre & Vol.7- $\mathrm{N}^{\circ} .1$ & $\begin{array}{c}\text { Junho } \\
2014\end{array}$ & p.67-78 \\
\hline
\end{tabular}


Fica claro, com essa citação, que valores éticos podem influenciar quais são os fatos que um cientista investiga, contudo, não é necessário que o pesquisador considere todo universo de valores éticos como relevantes para sua observação. $\mathrm{O}$ simples fato de existirem termos éticos estritos não obsta que se possam obter resultados imparciais, contudo, não se pode dizer que o resultado é sempre livre de qualquer carga valorativa, seja ela convencional ou ética.

Os empiristas que defendem a dicotomia fato-valor decerto refutam essa constatação. Os nãocognitivistas negam que existam conceitos éticos estritos, afirmado que se tratam de meros conceitos factuais, sem implicações éticas ou normativas. Assim, ao afirmarmos que alguém é valente, por exemplo, estamos diante de uma descrição (metafisicamente descomprometida) de um mero fato natural. Outro argumento seria o de que, caso existissem esses conceitos estritos, eles sempre seriam fatoráveis ou decomponíveis em uma descrição meramente atitudinal, desprovida de conteúdo valorativo. Assim, "cruel" representaria uma característica imputada a alguém, e não um juízo de valor acerca da pessoa. O juízo de valor seria uma significação que somente existiria pela perspectiva do locutor. Certamente isso não se sustenta:

The attempt of noncognitivists to split thick ethical concepts into a "descriptive meaning component" and a "prescriptive meaning component" founders on the impossibility of saying what the "descriptive meaning" of say "cruel" is without using the word "cruel" or a synonym.

A tentativa dos não-cognitivista de separar o conceito ético estrito em um “ componente descritivo de significado" e um "componente de significado perspectivo" desemboca na impossibilidade de se dizer que significado descritivo de, digamos, "cruel" existe sem o uso da palavra "cruel" ou de um sinônimo 7 .

Facilmente podemos identificar que as implicações da utilização da palavra "cruel" não podem ser reduzidas na definição: "aquele que causa grande sofrimento". Da mesma forma, "sofrimento" não significa somente "dor", nem "grande" pode ser definido com "quantidade elevada". Devemos, ainda, considerar o contexto, o que deixa a análise ainda mais complexa, reforçando o entrelaçamento entre fato e valor.

Putnam exemplifica que antes da invenção da anestesia um médico, ao realizar uma cirurgia, causava um "grande sofrimento" para o paciente, mas, ainda assim, não podemos dizer que se trata de um ato de crueldade. A solução não-cognitivista de ignorar a natureza ética e normativa de determinadas palavras não parece ser resposta válida para o problema apresentado, mas sim uma tentativa desesperada de manter viva a dicotomia fato-valor por meio de argumentos diferentes.

Como vimos anteriormente, para os empiristas clássicos um "fato" era, no fundo, somente algo traduzível numa impressão sensível, e a teoria humeana servia de base para que se pudesse apontar uma dualidade entre o que "era" e o que "deveria ser". Na modernidade, o empirismo foi substituído pelo positivismo lógico e pelas teorias de significado verificáveis, que fortificou a

${ }^{7}$ PUTNAM, Hilary. The collapse of the fact/ value dichotomy and other essays. Cambrige, MA: Harvard Press, 2002, p.38.

\begin{tabular}{|c|c|c|c|c|c|}
\hline intuitio & $\begin{array}{c}\text { ISSN } \\
1983-4012\end{array}$ & Porto Alegre & Vol.7 $-\mathrm{N}^{\circ} .1$ & $\begin{array}{l}\text { Junho } \\
2014\end{array}$ & p.67-78 \\
\hline
\end{tabular}


dicotomia entre fatos e valores. Essa transição não levou a um enfraquecimento da dicotomia fatovalor, mas sim se buscou justificar tal dualidade por meio de outros argumentos. Hoje, não estamos muito longe disso. Em que pese não mais se aceitar alguns dos velhos argumentos, correntes de pensamento como o relativismo não são senão novas formas nas quais podemos visualizar semelhantes dicotomias.

No fisicalismo, por exemplo, o que se defende é a existência de um conceito absoluto do que é o mundo. A premissa é que existiriam verdades independentes de perspectivas e observadores. Assim, cria-se uma dualidade entre o que "realmente é o caso" e aquilo que depende da perspectiva de outros. Essa posição não nega que sentenças éticas podem ser verdadeiras ou falsas, mas sim que elas não possam ser verdadeiras ou falsas independentemente de uma visão perspectiva de mundo. Por isso, tal posição teve de passar a se chamar relativismo, ao invés de não-cognitivismo.

Sejam elas posturas decorrentes de um posicionamento mais não-cognitivista ou de uma doutrina relativista, o que podemos constatar é que existem razões que nos tentam a pensar de forma dicotômica quando nos referimos a fatos e valores. Como pudemos ver ao longo da evolução teórica, a dicotomia fato-valor sempre encontrou uma maneira de permanecer vigorando. Mas quais são esses motivos que ainda nos levam a traçar essa linha divisória?

Primeiramente, existe a tendência de colocarmos os julgamentos valorativos fora da esfera da razão.

Com efeito, é muito mais simples rotularmos algo como um "julgamento de valor", e, portanto, classificarmos com apenas uma impressão subjetiva de alguém, do que fazer uma apreciação metafísica do que realmente somos, tentando verificar quais as implicações que resultam da valoração de uma determinada situação de fato. Esse exercício socrático de avaliarmos nossas convicções íntimas e testá-las em face da experimentação reflexiva com o compromisso de resolvermos nossas questões éticas não é um procedimento que desejemos a todo momento na nossa vida prática. Não há nada de errado nisso. Entretanto, podemos verificar que a utilização concreta da dicotomia fato-valor funciona como uma forma de "cortador de assunto". Quando "a" diz uma frase, "b" pode simplesmente assumir que o que foi dito é meramente a opinião de "a" e terminar o diálogo ali mesmo.

O que devemos resistir é à justificação de que não existe uma explicação metafísica sobre a possibilidade do conhecimento ético. Ora, a ideia de se procurar explicar o conhecimento ético normativo em termos absolutos é, em si, um absurdo. Ademais, o fato de não se poder encontrar definições em termos absolutos para conceitos eticamente estritos somente corrobora com a teoria de Putnam do entrelaçamento entre fato e valor.

A solução, portanto não pode ser uma que envolva conceitos inexoráveis nem distinções filosóficas que sejam dirigidas à formação de dicotomias. Não devemos desistir da discussão racional

\begin{tabular}{|c|c|l|l|l|l|}
\hline intuitio & ISSN & Porto Alegre & Vol.7 $-\mathrm{N}^{\circ} .1$ & $\begin{array}{l}\text { Junho } \\
2014\end{array}$ & p.67-78 \\
\hline
\end{tabular}


nem procurar um conceito "absoluto" que seja aplicado somente em determinados contextos que afastam situações difíceis.

Em conclusão, podemos dizer que somos tentados por várias razões a manter essa separação abrupta entre o que é fático-objetivo e o que é valorativo-subjetivo. Seja por motivos de ordem prática, funcional ou mesmo por comodidade filosófica, a busca por um conceito absoluto não pode sobrepujar os contextos e valores simplesmente para manter sua completude. Concordo com Putnam nesse aspecto: a solução deve sempre ser buscada de forma democrática, cooperativa e falível ${ }^{8}$.

\section{Economia, fato e valor - Putnam e Amartya Sen}

Putnam, para demostrar concretamente o entrelaçamento entre valor e fato, analisa a obra de Amartya Sen, economista e filósofo indiano, a quem é creditada a criação do IDH (Índice de Desenvolvimento Humano). Sen propõe uma releitura da "teoria econômica clássica", aduzindo que ela teria sofrido de um empobrecimento ético decorrente da sua estrutura excessivamente ligada à razão matemática e ao foco no interesse individual.

Os primeiros momentos da teoria econômica foram marcados por uma abordagem minimalista (a qual Sen denomina "abordagem de engenharia"), que desconsiderava os aspectos normativos e éticos da ciência econômica. Conforme Sen:

There are many issues on which economics has been able to provide better understanding and illumination precisely because of the extensive use of the engineering approach... these contributions have been made despite the neglect of the ethical approach, since there are importante economic logistic issues that do call for attention, and which can be tackled with efficiency up to a point, even within the limited format of a narrowly construed non-ethical view of human motivation and behavior ${ }^{9}$.

Existem muitas questões às quais a economia foi capaz de prover um melhor entendimento e iluminação precisamente por causa do uso extensivo da "abordagem de engenharia"... essas contribuições foram feitas apesar da negligencia quanto à abordagem ética, uma vez que há importantes problemas logísticos econômicos que chamam a atenção, e os quais podem ser atacados com eficiência, até certo ponto, mesmo dentro de um limitado formato de visão estritamente não-ética da motivação humana comportamental.

Se, nos séculos passados, era importante a perfectibilização dos aspectos matemáticos da abordagem minimalista da economia, Sen entende que hoje o importante é a correção da defasagem ética causada por essa mesma abordagem de engenharia. $\mathrm{O}$ empobrecimento da economia de bemestar estaria, dessa forma, relacionado ao distanciamento ético.

\footnotetext{
${ }^{8}$ PUTNAM, Hilary. The collapse of the fact/ value dichotomy and other essays. Cambrige, MA: Harvard Press, 2002.

${ }^{9}$ SEN apud PUTNAM, Hilary. The collapse of the fact/ value dichotomy and other essays. Cambrige, MA: Harvard Press, 2002, p 47/48.
}

\begin{tabular}{|c|c|c|c|c|c|}
\hline intuitio & $\begin{array}{c}\text { ISSN } \\
1983-4012\end{array}$ & Porto Alegre & Vol.7- $\mathrm{N}^{\mathrm{o}} .1$ & $\begin{array}{l}\text { Junho } \\
2014\end{array}$ & p. $67-78$ \\
\hline
\end{tabular}


A dicotomia fato-valor e seu colapso: um estudo a partir de Hilary Putmam

Para Sen, a obra de Adam Smith vem sendo mal interpretada através dos tempos. Muitos economistas ter-se-iam apegado à seguinte passagem do livro "A riqueza das nações" para justificar o império do interesse individual no campo econômico, o que restou por simplificar exageradamente a visão de Smith:

Não é da benevolência do açougueiro, do cervejeiro e do padeiro que esperamos o nosso jantar, mas da consideração que ele têm pelos próprios interesses. Apelamos não à humanidade, mas ao amor-próprio, e nunca falamos de nossas necessidades, mas das vantagens que eles podem obter ${ }^{10}$.

De fato, a ideia de que somente valores auto-interessados seriam racionais é recorrente na teoria econômica. Essa aproximação do racional com o egoísmo individual mostrou-se uma barreira para que se pudesse introduzir elementos éticos na economia. Por muitos anos a única ética que se podia encontrar na ciência econômica era a postura utilitarista, originária da doutrina de Jeremy Benthan, que responde todas as questões acerca do que fazer e de como viver, em termos da maximização da utilidade e da felicidade.

No âmbito filosófico, a posição utilitarista sempre sofreu muita resistência. Autores como Nozick e Rawls dedicaram parcela considerável de sua obra para tentar encontrar um modelo que fosse uma alternativa ao padrão utilitarista. O famoso experimento da "máquina de experiências" (no qual é dada a opção ao indivíduo de viver em uma máquina que simula todos os sentimentos ao invés de experimentar o mundo da forma convencional) foi a solução que Nozick opôs ao utilitarismo, na expectativa de tentar provar que o ser humano não age somente para maximizar seus interesses individuais.

A posição original de John Rawls foi outra forma de tentar evitar o utilitarismo. Nela as pessoas eram obrigadas, em razão do véu de ignorância, a colocarem-se na posição dos demais indivíduos excluídos ou menos favorecidos, o que afastaria a possibilidade de uma atitude utilitarista, uma vez que ao considerar uma soma total de utilidade a pessoa poderia estar legitimando o seu próprio sacrifício.

Sen também busca uma forma de desviar dessa ética exclusivamente utilitarista da ciência econômica. Ele tenta provar que o ser humano é movido, em diversas ocasiões, por motivos que não são auto interessados. E, além disso, estabelece que existe uma grande diferença entre valores genuinamente auto interessados de longo prazo e meros valores auto interessados imediatistas. Para isso, ele desenvolve uma teoria de liberdades positivas, que medem a real possibilidade das pessoas para cada atitude em sociedade, ao invés de focar em liberdades negativas, que somente estabelecem o que cada indivíduo não deve fazer. Tal teoria acabou sendo nomeada "abordagem das capacidades" (capabilities approach).

${ }^{10}$ SMITH, Adam. A riqueza das nações. São Paulo. Editora Nova Cultural Ltda, 1996, p 50.

\begin{tabular}{|c|c|c|c|c|c|}
\hline intuitio & $\begin{array}{c}\text { ISSN } \\
1983-4012\end{array}$ & Porto Alegre & Vol.7- $\mathrm{N}^{\mathrm{o}} .1$ & $\begin{array}{c}\text { Junho } \\
2014\end{array}$ & p.67-78 \\
\hline
\end{tabular}


Putnam enaltece a teoria das liberdades como capacidades, desenvolvida por Sen, especialmente porque ela não busca simplificar a realidade, utilizando-se do vocabulário comum para referir às capacidades humanas. Portanto, os termos que Sen utiliza na sua abordagem das capacidades são quase todos conceitos entrelaçados (conceitos éticos estritos), que não permitem uma decomposição em partes descritivas e valorativas.

Quando Sem fala em capacidades utiliza-se de expressões como: funções valoráveis, bem nutrido, mortalidade prematura, auto respeito, etc. Tratam-se de thick ethical concepts que, na visão do autor supracitado, devem passar a fazer parte da própria descrição do que é comportamento economicamente relevante. Portanto, a verdadeira economia de bem-estar deve estra intimamente ligada às mais modernas discussões éticas. E isso não é uma via de mão única, pois também a discussão ética pode ser enriquecida com o contato com a economia. Nas palavras conclusivas de Sen em seu livro "On Ethics and Economics":

I have tried to argue that welfare economics can be substantially enriched by paying more attention to ethics, and that the study of ethics can also benefit from a closer contact with economics. I have also argued that even predictive and descriptive economics can be helped by making more room for welfare-economic considerations in the determination of behaviour. I have not tried to argue that either of these exercises would be particularly easy. They involve deep-seated ambiguities, and many of the problems are inherently complex. But the case for bringing economics closer to ethics does not rest on this being an easy thing to do. The case lies, instead, on the rewards of the exercise. I have argued that the rewards can be expected to be rather large ${ }^{11}$.

Eu tentei arguir que a economia de bem-estar pode ser substancialmente enriquecida por prestar mais atenção à ética, e que o estudo da ética também pode se beneficiar de um contato mais próximo com a economia. Eu, da mesma forma, argui que, mesmo a economias descritiva e prescritiva, podem ser ajudadas por acolherem mais considerações da economia de bem-estar na determinação do comportamento. Eu não tentei arguir que qualquer desses exercícios seriam particularmente fáceis. Eles envolvem ambiguidade profundas e muitos problemas são hereditariamente complexos. Mas a questão de trazer a economia para mais perto da ética não está em ser fácil de se fazer. A questão está, invés, nas recompensas desse exercício. Eu argui que podemos esperar que as recompensas sejam bem significativas.

A teoria de Sen é mais honesta na medida em que não busca uma fórmula matematicamente descritível que resolva questões éticas e não éticas como um programa de computador. A ideia da abordagem das capacidades é justamente levar em conta que a economia também é uma ciência humana que lida com fatores éticos complexos os quais simplesmente não podem ser reduzidos a números e estatísticas. Segundo Sen a própria lista de funções valoráveis, representativas das reais possibilidades dos cidadãos, base para a teoria das capacidades, deve decorrer de discussão pública e aceitação democrática. Não se busca uma ordem completa capaz de representar o bem-estar geral do planeta, mas uma ordenação incompleta, que permita que possamos pensar o que realmente configura o bem-estar dentro de cada cultura.

${ }^{11}$ SEN, A. On ethics e economics. UK: Blackwell Publishing ,1988. p.89.

\begin{tabular}{|c|c|c|c|c|c|}
\hline intuitio & $\begin{array}{c}\text { ISSN } \\
1983-4012\end{array}$ & Porto Alegre & Vol.7- $\mathrm{N}^{\mathrm{o}} .1$ & $\begin{array}{c}\text { Junho } \\
2014\end{array}$ & p.67-78 \\
\hline
\end{tabular}


A dicotomia fato-valor e seu colapso: um estudo a partir de Hilary Putmam

Para que possamos atingir tal abordagem devemos deixar de compartimentalizar ética, economia e política. Ao assumirmos que o trabalho deve ser conjunto, democrático e falível, já estamos mais próximos de retratar uma realidade possível do que muitas análises econométricas que definem a renda per capta com base na riqueza total de um estado dividido pelo número de habitantes.

Tudo o que Putnam tentou demonstrar sobre o colapso da dicotomia entre fato e valor pode ser aplicado também à economia e às demais áreas dos conhecimento humano. $\mathrm{O}$ fato está entrelaçado ao valor assim como a ciência política é indissociável da ética. Qualquer tentativa de se abordar separadamente apenas um lado dessa dualidade resultará em uma apreciação incompleta, e indigna de representar a realidade.

\section{Referências}

ADORNO, Theodor. O ensaio como forma. In: Notas de Literatura 1. Trad. Jorge de Almeida. São Paulo. Ed. 34, 2008;

HUME, David. Ensaio sobre o entendimento humano (coleção os pensadores). São Paulo: Nova Cultural, 1999.

LACEY, Hugh. Valores e atividade científica. São Paulo: Discurso Editorial, 1998. $\overline{\mathrm{p} 251-266 .}$.

Relações entre fato e valor. Cadernos de Ciências Humanas - Especiaria. Vol 9, n 16, jul/dez, 2006,

MARICONDA, Pablo. Sobre as origens da dicotomia Fato e Valor e o controle da natureza. Scientia Studia 4,2006.

PUTNAM, Hilary. The collapse of the fact/ value dichotomy and other essays. Cambrige, MA: Harvard Press, 2002;

Representation and Reallity. Cambridge, MA: MIT Press, 1998.

Renovar a Filosofia. Coleção Pensamento e Filosofia. Portugal: Ed. Piaget, 1998.

Realism with a Human Face. Cambridge University Press, 1990.

Reason, Truth and History. Cambridge University Press, 1981.

SEN, Amartya. A idéia de Justiça. Trad. Denise Bottmann, Ricado Mendes. São Paulo: Companhia das Letras, 2011.

Desenvolvimento como liberdade. Trad. Laura Teixeira Motta. Revisão técnica. Ricardo Doninelli Mendes. São Paulo: Companhia das Letras, 2000.

On ethics e economics. UK: Blackwell Publishing, 1988.

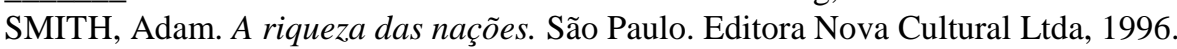

Recebido em: 15/10/2013

Aprovado para publicação em: 13/02/2014

\begin{tabular}{|c|c|c|c|c|c|}
\hline intuitio & $\begin{array}{c}\text { ISSN } \\
1983-4012\end{array}$ & Porto Alegre & Vol.7- $\mathrm{N}^{\mathrm{o}} .1$ & $\begin{array}{l}\text { Junho } \\
2014\end{array}$ & p. $67-78$ \\
\hline
\end{tabular}

